\begin{tabular}{|c|c|c|}
\hline $\begin{array}{l}\text { Tate Recaived by IRA } \\
\quad 9 / 5 / 97\end{array}$ & & $\begin{array}{l}\text { INFORMATION RELEASE REQUEST - (Long Form) } \\
\text { (GRAY SHADED AREAS NOT TO BE FILLED IN BY INITIATOR! }\end{array}$ \\
\hline \multicolumn{3}{|r|}{ 1. COMPLETE THIS SECTION FOR ALL DOCUMENTS } \\
\hline \multicolumn{2}{|c|}{ A. Information Category } & B. Document ID Number (include rev., vol, etc.) \\
\hline \multirow{2}{*}{$\begin{array}{l}\text { Speech or Presentation } \\
\square \text { Full Paper } \\
\square \text { Summary } \\
\square \text { Abstract } \\
\square \text { Visual Aid }\end{array}$} & \multirow[b]{2}{*}{$\begin{array}{l}\square \text { Journal Article } \\
\square \text { Multimedia Presentation } \\
\square \text { software }\end{array}$} & HNF-SA-3217-FP \\
\hline & & $\begin{array}{l}\text { c. List attachments ti.e.. copyright permission, copyright transter) } \\
\text { copyright transfer }\end{array}$ \\
\hline$\square$ other & & \\
\hline
\end{tabular}

D. Document Title

RE-ENGINEERING THE FEDERAL PLANNING PROCESS: A Total Federal Planning

Strategy, Integrating NEPA with Modern Management Tools

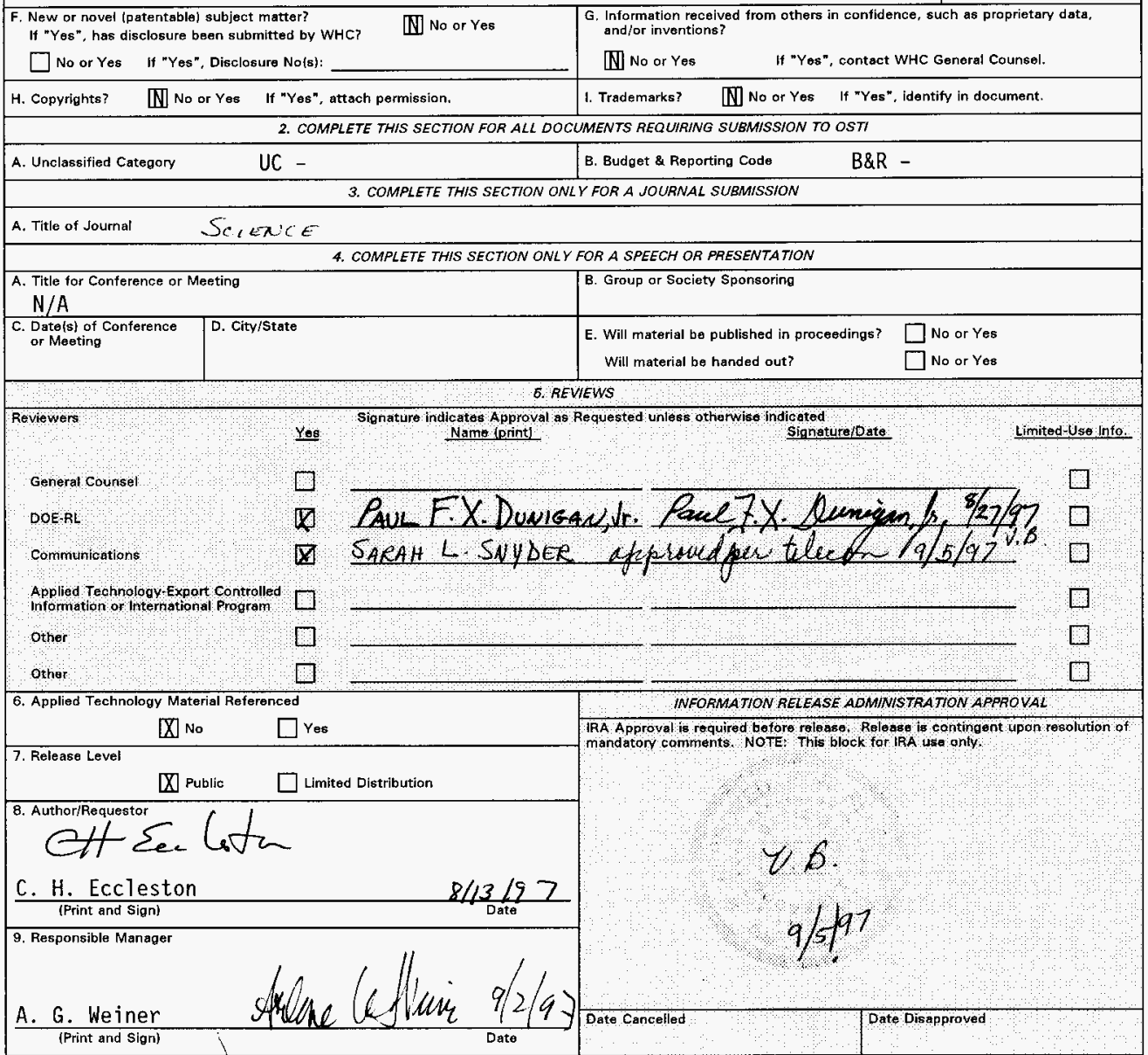


HNF-SA-3217-FP

Document ID Number

10. LEGENDSNOTTCESMARKINGS (Required by WHC-CM-3-4 or Reviewer) Revewor hidicates applicable markings to be affixed or romoved:

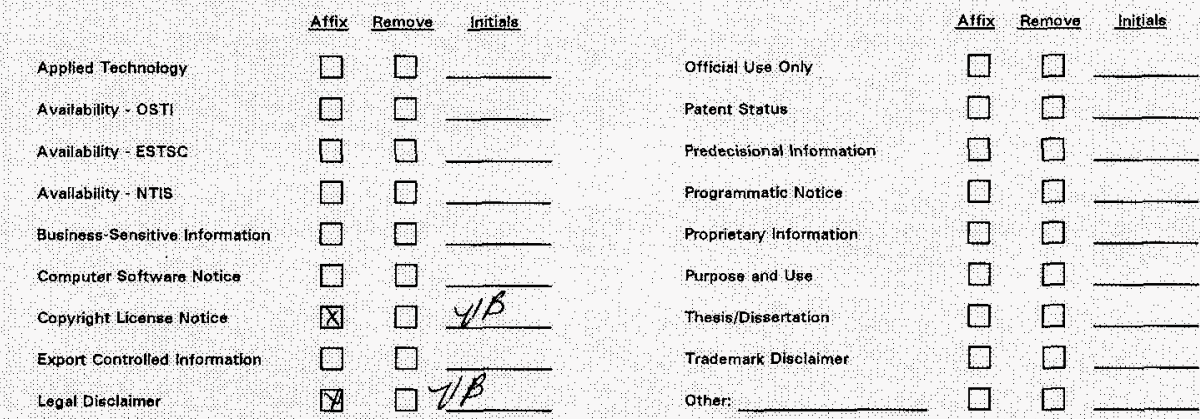

Limitad oisclosur

$\square \quad \square$ All other comments shall be modo on tho document and returned to the authar. 


\section{Re-Engineering the Federal Planning Process: A Total Federal Planning Strategy, Integrating NEPA with Modern Management Tools}

Prepared for the U.S. Department of Energy

Assistant Secretary for Environmental Management

Froject Hanford Management Contractor for the

U.S. Department of Energy under Contract DE-ACO6-96RL13200

Copyight Lioense By acceptence of this ericie, the publiaher andior recipient acknowledged the U.S. Government's right to retein a nonexdusive, royaty-freo license in and to eny copyright covering this peper.

Approved for public release; distribution is unlimited 


\title{
Re-Engineering the Federal Planning Process: A Total Federal Planning Strategy, Integrating NEPA with Modern Management Tools
}

\author{
C. H. Eccleston
}

Date Published

September 1997

Prepared for the U.S. Department of Energy

Assistant Secretary for Environmental Management

Project Hanford Management Contractor for the

Copyright Lioenem By acceptence of this erticle, the publisher and/or recipient ecknowiedges the U.S. Govemment's right to retein a nonexchusive, royety-fres licenee in end to my copyright covering this paper.

Approved for public release; distribution is unlimited 


\section{RELEASE AUTHORIZATION}

$$
\text { Document Number: HNF-SA-3217-FP }
$$

RE-ENGINEERING THE FEDERAL PLANNING PROCESS: A

Document Title: Total Federal Planning Strategy, Integrating NEPA with Modern Management Tools

This document, reviewed in accordance with DOE Order 1430.1D, "Scientific and Technical Information Management," and DOE G 1430.1D-1, "Guide to the Management of Scientific and Technical Information," does not contain classified or sensitive unclassified information and is:

\section{APPROVED FOR PUBLIC RELEASE}

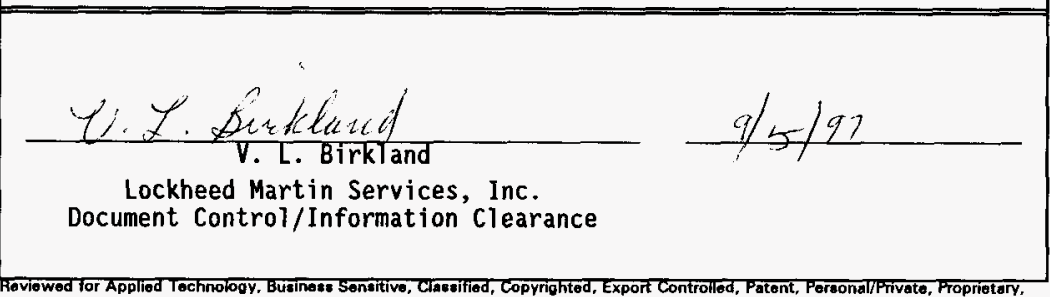

Protected CRADA, Tradomark, Unclassified Controlled Nuclear Information.

LEGAL DISCLAIMER. Thie report was prepared as en eccount of work eponeored by an soency of the United States Govemment. Neither the United States Govemment nor any agency thereof, not any of their employees, nor eny of their contractors, eubcontractors or their amployees, makes any warranty, exprese or implied, or ateumes any logal hability or responsibility for the accuracy, completenese, or any third party's ue or the resulte of euch ues of any information, epparatus, product, or procese dieclosed, or reprosents that ite use would not infringe privately owned righte. Reference herein to any specific commercial product, process, or eervice by trade name, trademark, manufacturer, or otherwiee, does not necescarily conetitute or imply its endoreement. recommendation, or fevoring by the United States Government or any sgency thereof or ke contractore or subeontrectore. The viows and opinions of euthors expreseed herein do not necesearily otate or reflect those of the United States Government or any agency thereof. This report has been reproducod from the bett avalleble copy. Printod in the United States of America. Available to the U.S. Department of Enerdy and ite contrectore from the U.S. Department of Energy Office of Scientific and Technical Information, P.O. Box 62. Oak Ridge, TN 37831: Telephone: 423/676-8401.

Available to the public from the U.S. Department of Commerce National Technical Information Service, 6286 Port Royel Roed, Springfiold, VA 22161; Tolephone: 703/487-4650. 


\title{
RE-ENGINEERING THE FEDERAL PLANNING PROCESS
}

\section{A Total Federal Planning Strategy, Integrating NEPA with Modern Management Tools}

\author{
Charles H. Eccleston
}

\begin{abstract}
The National Environmental Policy Act (NEPA) of 1969 was established by Congress more than a quarter of a century ago, yet there is a surprising lack of specific tools, techniques, and methodologies for effectively implementing these regulatory requirements. Lack of professionally accepted techniques is a principal factor responsible for many inefficiencies. Often, decisionmakers do not fully appreciate or capitalize on the true potential which NEPA provides as a platform for planning future actions. New approaches and modern management tools must be adopted to fully achieve NEPA's mandate.

A new strategy, referred to as Total Federal Planning, is proposed for unifying large-scale federal planning efforts under a single, systematic, structured, and holistic process. Under this approach, the NEPA planning process provides a unifying framework for integrating all early environmental and nonenvironmental decisionmaking factors into a single comprehensive planning process. To promote effectiveness and efficiency, modern tools and principles from the disciplines of Value Engineering, Systems Engineering, and Total Quality Management are incorporated. Properly integrated and implemented, these planning tools provide the rigorous, structured, and disciplined framework essential in achieving effective planning.

Ultimately, the goal of a Total Federal Planning strategy is to construct a unified and interdisciplinary framework that substantially improves decisionmaking, while reducing the time, cost, redundancy, and effort necessary to comply with environmental and other planning requirements. At a time when Congress is striving to 're-engineer' the governmental framework, apparatus, and process, a Total Federal Planning philosophy offers a systematic approach for unifying the disjointed and often convoluted planning process currently used by most federal agencies. Potentially this approach has widespread implications in the way federal planning is approached.
\end{abstract}

\section{A NEW APPROACH FOR FEDERAL PLANNING}

Concinnity (kun SIN $i$ tee) is the act of blending distinct elements, so skillfully, as to form an elegant and harmonious whole. Concinnity, or the blending of all relevant decisionmaking factors 
into a single comprehensive process, is a component essential to the success of any comprehensive and holistic planning process. Planning processes that fail to blend pertinent decisionmaking factors are destined to experience disconnects or redundancies, ultimately leading to costly or ineffective actions. Conceptually unpretentious and alluring in its simplicity, concinnity is not often realized in the real world setting of federal planning.

\section{DIFFICULTIES WITH THE NEPA PLANNING PROCESS}

In creating the National Environmental Policy Act (NEPA) of 1969, Congress laid the foundation for a comprehensive planning framework applicable to all federal actions. As prescribed by NEPA, federal agencies must prepare an Environmental Impact Statement (EIS), evaluating impacts and alternatives before making a final decision to pursue a major federal action significantly affecting the quality of the human environment. ${ }^{1}$

The Council of Environmental Quality's (CEQ) regulations mandate explicit requirements governing the preparation of an EIS ${ }^{2}$ Yet, there is a distinct difference between specifying "what" procedural requirements must be satisfied, versus "how" such requirements are actually implemented. The NEPA regulations are quite explicit in specifying what procedural requirements must be met. In promoting a flexible process that can be tailored to a diverse array of federal projects, agencies are granted unusual latitude in determining how such requirements actually will be implemented.

As NEPA nears its third decade, no rigorous and structured general-purpose approach has been established for determining how these regulatory requirements are most effectively implemented. At best, only marginal progress has been witnessed in developing or integrating modern tools, methods, and procedures so that the EIS process is conducted more efficiently and effectively. Given the current political climate, increasingly centered on 're-engineering' government processes, the time is ripe for embracing modern tools, techniques, and methodologies. New approaches, incorporating modern methodologies for harnessing NEPA's untapped potential to facilitate federal planning are needed, if NEPA is to truly achieve the goals Congress laid out over a quarter century ago. Interestingly, the NEPA regulations provide specific methods and directions that provide the basis for a general-purpose planning process. The strategy that is introduced shortly, takes advantage of NEPA's flexibility, as it proposes a general-purpose approach, focusing on "how" agencies can most effectively integrate NEPA into federal planning.

\section{TOTAL FEDERAL PLANNING}

A new and comprehensive approach for conducting federal planning, referred to in this paper as the Total Federal Planning (TFP) strategy, is advanced, having potentially widespread implications in the way planning is managed at the federal level. This approach advocates a single, structured, integrated, and comprehensive framework for planning major federal actions, 
incorporating modern principles from disciplines of Systems Engineering (SE), Value Engineering (VE), and Total Quality Management (TQM). Table 1 summarizes the succinct benefits and features of TFP.

\section{Table 1. Principal Features Underlying the Total Federal Planning Process.}

- The Total Federal Planning process is holistic, combining and integrating early planning efforts into a single, interdisciplinary, unified planning process conducted under the NEPA umbrella. This enhances ability to determine an optimum course of action; increases understanding of interrelationships; reduces redundancies, miscommunications, and problems that may otherwise go unrecognized; and enhances understanding of infrastructure and resource requirements.

- Nonenvironmental studies are included as part of the EIS or in supporting documents integrated with the NEPA analysis.

- All planning factors relevant to making an informed decision are evaluated within a single integrated interdisciplinary analysis (environmental, cost, legal, performance specifications, schedules, technical capability).

- The early planning process is performed independently of project proponents. An independent Interdisciplinary Steering Team (IST) oversees the planning process, enhancing objectivity and the ability to identify an optimum course of action.

- The IST identifies a set of alternatives that are developed in sufficient detail to support analysis by a project or engineering office and analyzed by an Interdisciplinary Team.

- The IST and Interdisciplinary Teams (IDT) define data requirements that will be developed by the project or engineering office.

- A proposed action is not defined. Instead, a set of reasonable alternatives are identiffed for analysis. Emphasis is placed throughout the process on optimizing potential alternatives.

- The planning process is conducted under the NEPA umbrella using modern management tools and principles such as:

- Systems Engineering provides rigorous methodology, useful in systematically managing and analyzing complex operations while minimizing schedule and cost constraints.

- Total Quality Management promotes optimization of alternatives, accountability, data adequacy, and integrity of the analysis.

- Value Engineering tools are incorporated in objectively identifying, reviewing, discriminating, and prioritizing various planning factors and options, and in reaching group consensus. 
The TFP process is designed to improve decisionmaking by creating a unified and interdisciplinary framework under which all environmental and nonenvironmental planning is welded together. The NEPA process is used as a centralized framework for fusing the relevant decisionmaking factors and requirements into a single, integrated planning process. Principles from SE and VE provide a structured foundation for instilling a rigorous and disciplined approach, essential for maintaining an effective planning process. Principles from TQM provide a basis for optimizing alternative courses of action and ensuring integrity and accuracy in the final product. Before considering a new approach, some of the problems commonly encountered in implementing the NEPA process are examined.

\section{COMMONLY ENCOUNTERED PLANNING PROBLEMS}

All too often, federal planning is fragmented, uncoordinated, narrowly focused, or lacks cohesion (concinnity), sufficient to furnish decisionmakers with a comprehensive picture and analysis, essential to reaching an informed decision. Decisions are often made in a 'vacuum,' lacking rigorous consideration of other pertinent planning factors. Still other problems stem from the fact that NEPA has not been properly "integrated" or "combined" with other federal planning processes, or pursued during the "early" planning phase, as required by the regulations. ${ }^{3}$ Table 2 summarizes commonly reported problems.

Compounding such problems is the fact that NEPA is often viewed more as a 'permitting' requirement for documenting decisions already made, than as a true planning process. As indicated by the sixth and seventh item in Table 2, alternatives often are not given consideration equivalent to that of the proposed action. In some cases, alternatives lying outside a particular mind set are often given only cosmetic treatment.

Project proponents, having vested interest in the outcome of a decision, often exert influence in favor of a particular course of action (e.g., typically, the proposed action). Once sufficient momentum is reached, inertia drives decisionmaking in favor of the proposed action, even in cases where more optimum alternatives might exist (in terms of both environmental and nonenvironmental advantages). More optimum alternatives have also been overlooked because the planning process was not conducted as an "open," "interdisciplinary," "rigorous," or "systematic" manner. ${ }^{4}$ Examples abound where superior alternatives have either gone unnoticed or fallen by the wayside, primarily because they have not complied with the very requirements that promote rigorous and effective planning.

Not surprisingly, NEPA's proven ability (when properly implemented) to provide a framework for comprehensive long-term planning often goes unexploited. Such practice often leads to uncoordinated and even conflicting plans. As a consequence, planning can be a vertiginous process, subject to ceaseless change, modification, and revision. 
Table 2. Commonly Observed Problems in NEPA and the Federal Planning Process.

\author{
Uncoordinated plans \\ Failure to view planning from a holistic standpoint \\ Failure to blend pertinent planning factors together (i.e., lack of concinnity) \\ Incomplete information \\ Infrastructure inconsistencies and incompatibilities \\ Failure to identify or rigorously pursue optimum solutions and alternatives \\ Lack of impartiality in analyzing proposed action versus reasonable alternatives \\ Failure to identify or plan for cross-cutting issues \\ Inability to identify long-term inconsistencies with other projects \\ Inability to identify all regulatory and planning requirements \\ Unreliable projections and poor forecasting \\ Miscommunications.
}

Some critics charge that NEPA is an inefficient process. Inefficiency is not indigenous to the NEPA process per se. To the contrary, the root problem lies principally in the approaches used and because modern management tools, techniques, and methodologies have not been developed or adopted for implementing NEPA's requirements. A fresh approach, incorporating modern management tools and principles, is long overdo.

\title{
NEPA PROVIDES A GENERAL-PURPOSE FRAMEWORK FOR INTEGRATING PLANNING
}

Among the broad array of federal planning and compliance requirements, NEPA is unique. NEPA is the only federal planning process that is both mandated and applicable to all "major" federal actions. From its inception, NEPA was envisioned to provide a framework, sufficiently flexible, so that it could be molded and adapted to meet the diverse missions and specific circumstances of any federal agency. Echoing this philosophy, the Regulations were specifically written to provide agencies with such flexibility. Nearly three decades after NEPA's enactment, the Act and its implementing regulations continue to provide the basic elements, flexibility, and framework essential for welding a diverse array of planning considerations into a single, comprehensive, and integrated planning process. 


\section{NEPA PROVIDES ALL ELEMENTS NECESSARY FOR GENERAL-PURPOSE PLANNING}

As depicted in the left hand column of Table 3, NEPA contains the essential elements, requisite to the success of any general-purpose planning process. For example, agencies are instructed to integrate NEPA with other environmental reviews so as to "...run concurrently rather than consecutively...," thereby avoiding duplication of effort, delays in compliance, and minimizing cost. ${ }^{5}$ The regulations direct agencies to coordinate and "...integrate the NEPA process with other planning at the earliest possible time..." Moreover, the "heart" of the NEPA planning process is the requirement to provide an open, unbiased, evaluation of "all reasonable alternatives."

As the only general-purpose planning process required for all major federal actions, NEPA provides the underlying "Tao" (path) for achieving concinnity. The flexibility that NEPA provides as a general-purpose planning tool has gone largely unrecognized. As described shortly, the TFP strategy provides an integrated approach under which all relevant decisionmaking factors (e.g., cost, safety, schedules, risk, technological constraints, and regulatory requirements) are considered together within a single interdisciplinary framework. Environmental considerations are only one of many factors evaluated.

By integrating detached federal requirements into an integrated process, decisionmakers have a more comprehensive, realistic, and reliable picture of alternatives, and perhaps most importantly, more optimum courses of action to choose from. Integrating NEPA with other planning and environmental requirements minimizes duplication of effort and increases general efficiency.

\section{IN PURSUIT OF AN OPTIMUM ALTERNATIVE}

As explained earlier, a planning process which is skewed towards analysis of a proposed action is less likely to identify an optimum course of action. In promoting a truly open and unbiased planning process, the TFP avoids the standard step of identifying a proposed action. This approach avoids even the use of the term "proposed action." Instead, a range of reasonable alternatives are developed, each given fair and equitable consideration, in an endeavor to identify an optimum alternative. The term optimum alternative refers to the alternative that best meets all relevant environmental and nonenvironmental planning factors (e.g., cost, schedules, environmental impacts, performance factors, technical factors).

This approach has many advantages, some of which could result in substantial cost savings. Because this approach promotes a more open, independent, and interdisciplinary process, the agency stands a greater chance of identifying innovative and perhaps more cost-effective alternatives that might otherwise be overlooked. Before considering the TFP process in detail, a repertoire of modern tools and techniques is described that can be applied to promote a more effective planning process. 


\section{MODERN ASSESSMENT TOOLS AND MANAGEMENT PRINCIPLES ARE NEEDED}

A repertoire of modern tools and techniques are key to increasing effectiveness of the federal planning process. The following sections provide a summary of principles and tools that are integral to the TFP philosophy.

\section{VALUE ENGINEERING PROVIDES TOOLS FOR INCREASING EFFICIENCY AND EFFECTIVENESS}

The concept of VE was pioneered to identify substitutes for scarce materials at the close of World War II. Today, VE provides a practical set of tools for investigating root problems, formulating alternatives, and identifying optimum solutions. A VE facilitator typically leads an interdisciplinary team through a number of rigorous procedures designed to identify alternatives or solutions to a problem. The team is challenged to break down preconceived and prejudicial notions and to consider new and alternative concepts that lead to better solutions. ${ }^{8}$

\section{The Connection Between VE and NEPA}

Because of its proven ability to increase efficiency and reduce cost, the Office of Management and Budget (OMB) has recently directed federal agencies to apply VE in planning major federal projects exceeding 1 million dollars. ${ }^{9}$ As a result, NEPA and VE are both mandated to be performed on major federal projects. Is this simply another case where the government has mandated overlapping and redundant requirements?

VE is not a planning process. To the contrary, VE provides a 'tool box' of problem solving techniques for analyzing problems and identifying solutions. In contrast, NEPA provides a comprehensive planning process, but lacks the intrinsic tools for effectively implementing its procedural requirements. Thus VE offers a tool for managing various steps in NEPA process To date, this connection appears to have gone unrecognized. An integrated approach is advantageous because it provides an efficient means for complying with both CEQ and OMB mandates.

Table 3 compares principal characteristics and goals of NEPA with those of VE. While NEPA and VE share strikingly similar goals and requirements, these are not redundant. Not only are NEPA and VE compatible, they in-fact complement one another. Commonality in these goals provides a foundation in which VE can be used as a tool for increasing effectiveness of the NEPA planning process. 


\begin{tabular}{|c|c|}
\hline EIS & VE \\
\hline $\begin{array}{l}\text { Requires use of a "Public"10, unbiased", and } \\
\text { "rigorous" process }{ }^{12}\end{array}$ & Based on an unbiased and rigorous process. \\
\hline $\begin{array}{l}\text { Is predicated on use of a "systematic } \\
\text { interdisciplinary" approach. }{ }^{13}\end{array}$ & Uses a systematic and interdisciplinary process. \\
\hline $\begin{array}{l}\text { "Combines"14 other federal planning processes } \\
\text { during the "early"15 planning phase. }\end{array}$ & Encompasses all pertinent planning factors. \\
\hline $\begin{array}{l}\text { EISs must be prepared early enough, so to serve as } \\
\text { an important contribution to decisionmaking. An } \\
\text { EIS is not to be used to rationalize or justify } \\
\text { decisions already made. }{ }^{16}\end{array}$ & $\begin{array}{l}\text { VE should be applied early enough to assist in } \\
\text { decisionmaking. It is not intended to justify } \\
\text { decisions already made. }\end{array}$ \\
\hline $\begin{array}{l}\text { An EIS analysis must provide a "full and fair } \\
\text { discussion" of impacts and reasonable } \\
\text { alternatives. }\end{array}$ & Necessitates a full and fair analysis of alternatives. \\
\hline $\begin{array}{l}\text { An EIS must explore and objectively evaluate all } \\
\text { reasonable alternatives. }{ }^{18} \text { Alternatives form the } \\
\text { "heart" of an EIS. }{ }^{19}\end{array}$ & Promotes consideration of all possible alternatives. \\
\hline $\begin{array}{l}\text { NEPA is the only federally mandated planning } \\
\text { process, applicable to all major federal actions. }\end{array}$ & $\begin{array}{l}\text { The Office of Management and Budget has } \\
\text { mandated that VE be applied to the planning of all } \\
\text { major projects. }\end{array}$ \\
\hline NEPA is a planning process. & VE provides management tools useful in planning \\
\hline $\begin{array}{l}\text { NEPA allows the consideration of cost and other } \\
\text { factors in the analysis and decisionmaking process. }\end{array}$ & $\begin{array}{l}\text { VE considers all pertinent planning requirements } \\
\text { (e.g., cost, schedule, environmental). }\end{array}$ \\
\hline
\end{tabular}

\section{SYSTEMS ENGINEERING PROVIDES PRINCIPLES FOR CONDUCTING STRUCTURED PLANNING}

Principles underlying SE surfaced in the aerospace industry in the mid-1950's. SE is a management process used to control planning and development of complex systems. A disciplined process is used to transform a need into a set of integrated parameters, used to optimize the effectiveness of a system. ${ }^{20}$

There is a subtle but important distinction between the goals of SE and NEPA. While NEPA provides a comprehensive process for planning and decisionmaking, SE provides a structured methodology for identifying, investigating, and developing alternatives. These differences aside, the structured management and design principles inherent in SE provide principles essential in 
maintaining efficiency within a complex planning process. As described later, SE provides a systematic tool for developing optimum alternatives and analyzing impacts and various decisionmaking factors.

\section{TOM PROVIDES PRINCIPLES FOR ENSURING INTEGRITY AND OPTIMIZING PLANNING}

One of the objectives of TQM is to break down unnecessary barriers between groups, organizations, and various disciplines. A modified Deming Cycle, consisting of five distinct phases: Plan-Do-Study-Act-Support, provides a basis for improving a system. During the planning phase ideas are generated and developed to improve a system or component. The change is implemented during the Do phase and Studied to evaluate its effectiveness. If the results prove to be less than intended, the process returns to the planning phase. Actions necessary to adopt the improvement are made during the Act phase. To be effective, there must be a desire to optimize the process (e.g., developing an optimum course of action). The Support phase captures the desire by indicating that management must support this process if it to prove effective.

To ensure that decisionmakers have accurate information and optimum alternatives to choose from, TQM principles are adopted at critical stages throughout the TFP strategy. Feedback loops are incorporated to improve and optimize the planning process. As described in the following section, NEPA provides the flexibility and framework necessary for incorporating VE, SE and TQM tools and principles into an integrated federal planning process.

\section{TOTAL FEDERAL PLANNING: A GENERAL-PURPOSE STRATEGY FOR INTEGRATING FEDERAL PLANNING}

As presented, concinnity is an element essential to the success of a general-purpose planning process. A holistic strategy incorporating all pertinent steps necessary to address problems commonly encountered in federal planning is now introduced. TFP can be viewed as consisting of three underlying concepts: (1) the NEPA process which provides the unifying framework for achieving concinnity; (2) a structured and systematic approach for integrating planning, addressing problems described in Table 2; and (3) modern management tools and principals that are incorporated throughout this strategy to facilitate efficiency and effectiveness. VE is used to identify and manage important information and factors, while TQM principles are used to optimize alternatives and to ensure quality in the planning process. SE is used as a unifying tool for integrating and conducting the investigation of alternatives and various other aspects of the analysis.

Properly conceived and executed, this approach reduces mis-communication and redundancy. Potential conflicts are easier to identify and diagnose. Communication is enhanced because 
representatives from all relevant planning disciplines, including the project proponents, are integrated into a single planning process. Potential delays and design inconsistencies are minimized because associated infrastructure and regulatory requirements are accurately identified early in the process. Tradeoffs and interrelationships are easier to identify and analyze. Finally, the chance that an important consideration or problem could be overlooked is greatly diminished. Utimately, such benefits translate into expedited project implementation, less redundancy, and resource and cost savings.

The TFP strategy is specifically designed for large, complex planning requiring preparation of an EIS. This strategy complies with all NEPA regulatory requirements for preparing EISs. While TFP is not designed to be used for small or relatively uncomplex projects, agencies could still benefit in applying certain aspects of this strategy to project planning. Professional judgment must be exercised in the application of this model.

The TFP strategy is specifically designed to address problems depicted in Table 2. Table 1 summarizes the intrinsic advantages and features. The strategy is designed to provide planners/decisionmakers with flexibility and freedom to customize and adapt this approach to their particular needs. Thus, this model can be modified and tailored, on a case-by-case basis, to accommodate existing circumstances. The TFP strategy is specifically designed for projects directly undertaken by the federal agency and could require modification where actions involve private or nonfederal applicants. ${ }^{21}$

\section{OVERVIEW OF THE TOTAL FEDERAL PLANNING STRATEGY}

Figure 1 provides an overview of TFP. The thin arrows indicate the flow of information, as well as how pertinent planning entities and functions are integrated into a centralized planning process. Bold arrows depict the integration, relationships, and decisionmaking flowpaths between the IST, IDT, project proponent, and decisionmaker. Relationships depicted by the bold arrows are specifically designed to inject objectivity, accountability, and quality into the final decisionmaking process.

When a need for action is identified, an IST is formed, with responsibility to guide and provide independent oversight of the entire planning process. The IST is composed of representatives from pertinent planning and decisionmaking organizations. All planning functions are coordinated though the IST. Thus, planning entities and functions that are often detached from one another are integrated into a centralized interdisciplinary planning format. Under this approach, $N E P A$ provides an 'umbrella' for integrating various planning efforts and requirements into a single, unified framework, under oversight of the IST. Responsibility for determining which alternatives will be evaluated lies with the IST. The IST defines the set of alternatives and decisionmaking factors must be investigated to provide information necessary to reach an informed decision. As described later, the IST also plays a prominent role in integrating TQM principles into the TFP, thus ensuring quality of the final product. 


\section{A COORDINATED APPROACH TO HOLISTIC PLANNING}

Once agreement is reached on the range of alternatives, the IST provides design specifications to the project proponent (arrow "Provide design requirements", Figure 1). Based on requirements defined by the IST, a project proponent (e.g., engineering or design office) develops the reasonable alternatives, including any engineering or design data, to a stage sufficient to support an analysis of the alternatives. A systems engineering approach is used for generating this data. The completed data package is transmitted back to the IST (arrow "Completed engineering and design Package", Figure 1), which is responsible for checking the analysis for completeness and accuracy before the information is provided to the IDT .

To provide an open and objective evaluation, the actual analysis of alternatives is conducted by an IDT. The IST provides the IDT with technical information (arrow "Input data", Figure 1) that was generated by the project proponent. The IDT investigates and compares both environmental and nonenvironmental considerations critical to making a reasoned decision regarding the course of action to be taken. The IDT prepares an integrated EIS for the IST (arrow "Completed analysis", Figure 1). The analysis is coordinated and conducted with support from the project proponent (engineering/design office). Where appropriate, a systems engineering approach could provide the underlying methodology for performing the analysis. The final product is an EIS that considers both environmental and nonenvironmental factors, or an EIS tightly coupled to other pertinent planning studies.

The IST checks the analysis for completeness and accuracy before the EIS (or integrated planning study) is provided to the decisionmaker for consideration (arrow "Recommendation", Figure 1). On completing the review of the planning studies, the IST may recommend an appropriate course of action to the responsible decisionmaker. The final decision lies with the responsible decisionmaker (arrow "Choose course of action. Issue ROD", Figure 1) which is recorded in the agency's ROD. Once the final decision is recorded, control is passed to the project proponent who is responsible for conducting any detailed designs or studies necessary for implementing the decision (arrow "Project office/advocate implements decision", Figure 1).

Figure 2 provides a generalized flow chart of the standard NEPA process, allowing the reader to compare the description of the TFP approach, beginning in the next section, with the standard NEPA process. The TFP strategy is portrayed in Figures 3 through 7 , and complies with all applicable EIS regulatory requirements. Figures 3 through 7 provide the detailed step-by-step structured process for implementing the planning strategy illustrated in Figure 1. As depicted in these figures, the TFP strategy consists of six distinct phases: Pre-scoping, Formal Scoping, Data Development and Design, Optimization and Data Validation, Analysis, and Review and Decisionmaking. While a scattered number of cases exist where certain features of the TFP model are used, documented cases have not been identified where this strategy has been implemented comprehensively. 


\section{PRE-SCOPING PHASE}

Once a need for action is identified, a Pre-Scoping Phase (Figure 3) is initiated. Information gathered during this step provides a coherent basis for explaining the need to take action and the potential alternatives. This phase can enhance the agency's credibility, once the agency enters into the public scoping that follows this phase. Specifically, the pre-scoping phase attempts to identify potential alternatives and impacts, resource and infrastructure requirements, related regulatory requirements, and potential controversy that might be encountered during the formal scoping process. A description of this phase follows.

\section{ASSEMBLING AN INTERDISCIPLINARY STEERING TEAM}

Special measures are incorporated into TFP to ensure that an open and impartial planning process is conducted, and that ALL reasonable alternatives are considered and given fair treatment. Independence is a prime requirement for success. Accordingly, control of the planning process is detached from project proponents who might have a vested interest in the outcome of the final decision.

To this end, an IST is formed to oversee the planning process, ensuring that an open and impartial planning process is conducted that 'truly' explores all reasonable alternatives. The IST is viewed as a small non-permanent team of specialists representing a diverse spectrum of disciplines (e.g., environmental, risk assessment, project engineering, safety, health, regulatory, infrastructure, legal, economic, and SE and VE engineering) relevant to the particular planning process at hand. A new IST could be formed to oversee each major project that arises.

The IST oversees the entire planning process, from conception to the point where a final decision is made. On completing the planning process, the IST is dissolved and responsibility for implementing the final decision is turned over to the project office or project proponent. Given its temporary status and interdisciplinary nature, there is less chance that an IST will become 'institutionalized', or be influenced by vested interests or organizational agendas. Thus, this approach is mors likely to unearth an optimum course of action.

The concept of an IST is a new feature distinguishing this approach from most other planning approaches and processes. While the IST is independent of project proponents, project proponents are represented and included as an integral part of the team. However, while project proponents provide input and are given representation, they do not control the planning process. Instead, engineering and project proponents are given responsibility for conducting design studies only after the IST has consensus regarding the range of alternatives that will be evaluated. 

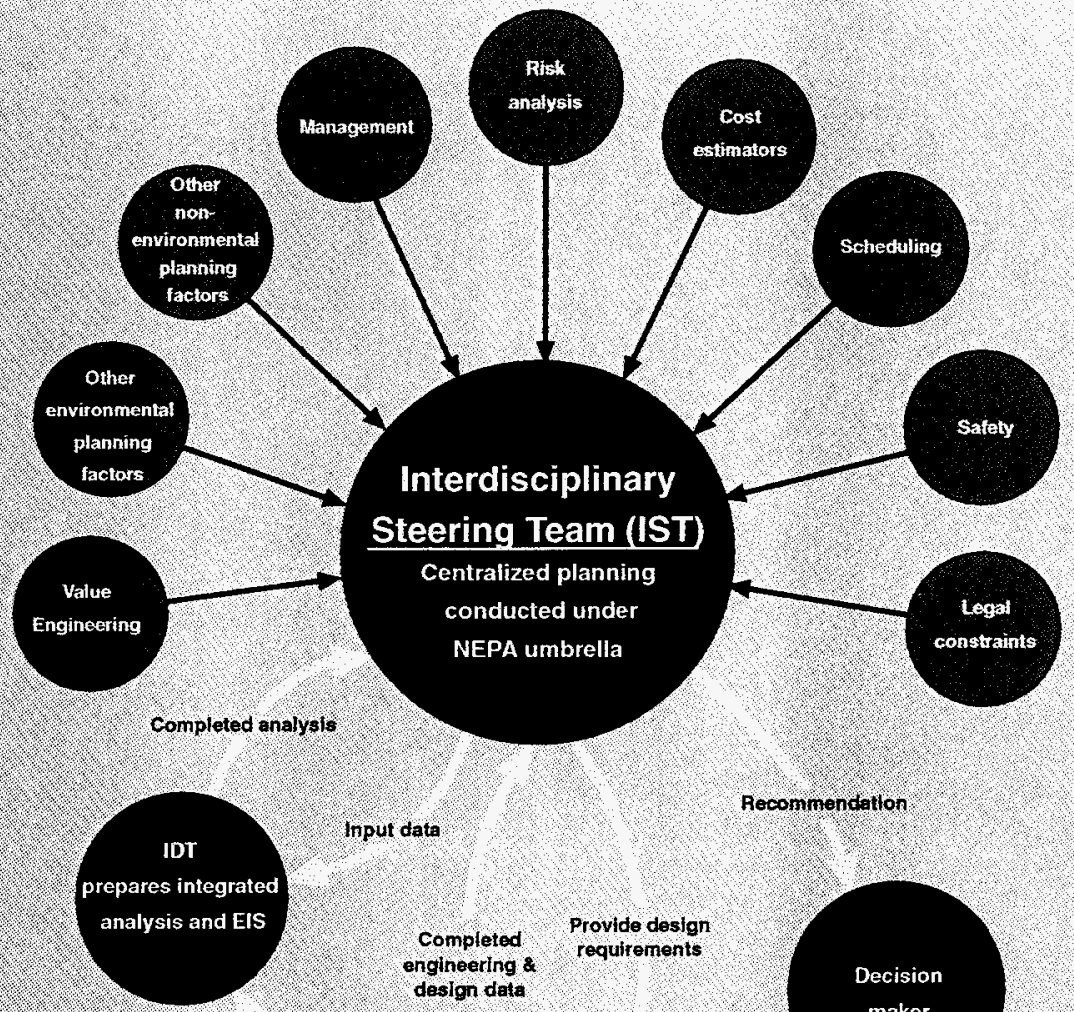

Inpuf data

Hecommendation

Systems

Engineering

Completed enginoering ? design data

Provide design requirements

Decision

maker
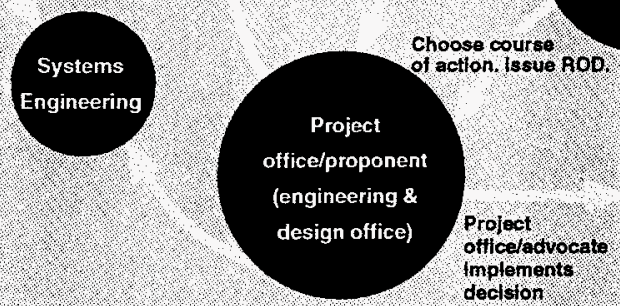

Implement

decision

mements deciston

\section{EIS . - 0 Environmental Impact Statement \\ IDT - - . Interdisciplinary Team \\ IST $=4$ interdisciplinary Steering Toam \\ nOo $=$. Record of Decision}

$1970103491(\mathrm{C})$

Figure 1. Overview of the Total Federal Planning Strategy. Integrating all Early Planning Under and independent IST. 


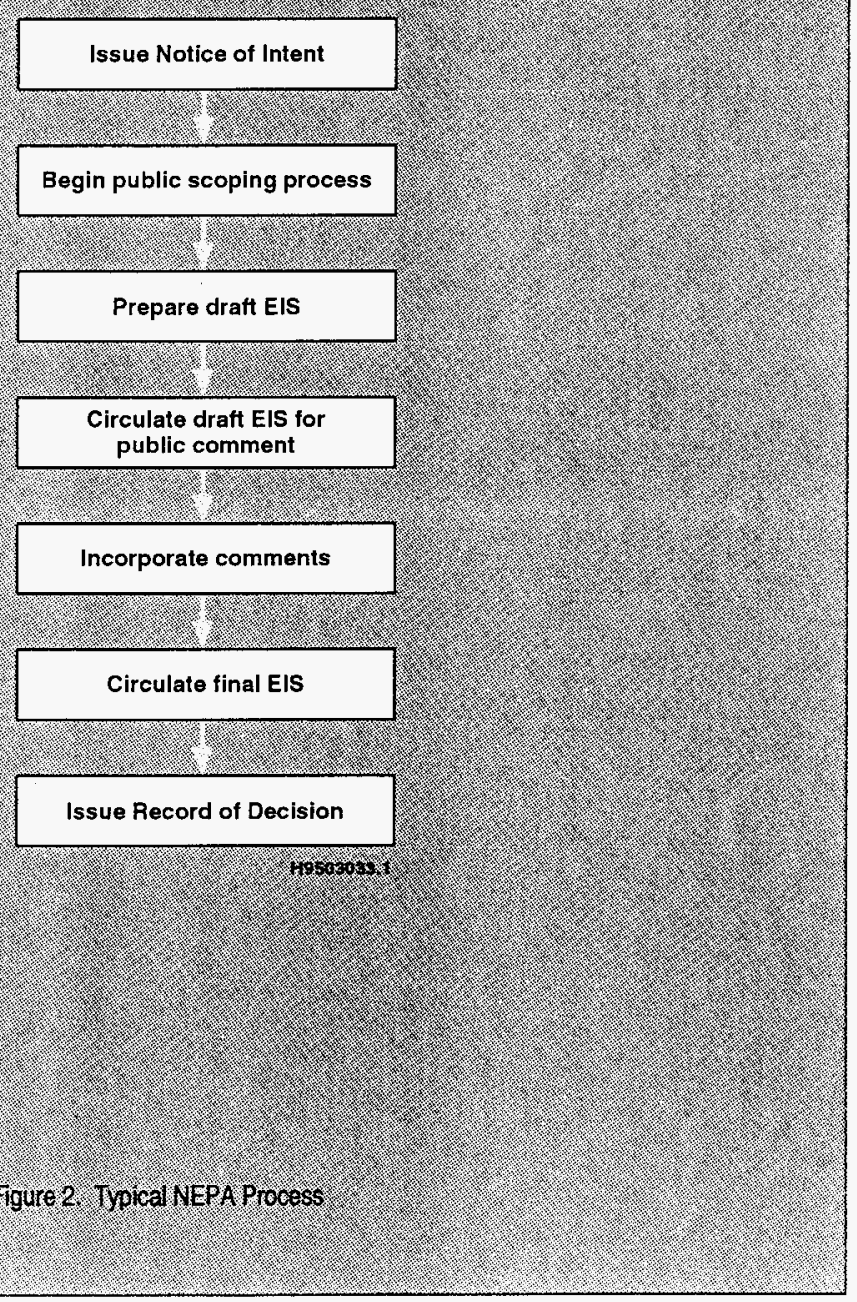


Assemble Interdisciplinary Steering Team (IST)

VE Workshop
- Identify all pertinent
disciplines or planning
requirements that need to
be included
- Define "Purpose and Need"
- Develop FAST Diagram of
No-Action Alternative
(if warranted)
- Identify functional
relationships and
requirements
- Brainstorming Stage (identify
preliminary alternatives
issues/impacts)
- Identify nonenvironmental
planning factors to be considered
as part of the integrated
planning process

- Additional Internal Scoping (as Appropriate)

- Develop regulatory requirements matrix

- Determine that an EIS is appropriate

- Issue NOI

1.0. 4.0 .036 .

Fourot Pro Scoping Fhase 


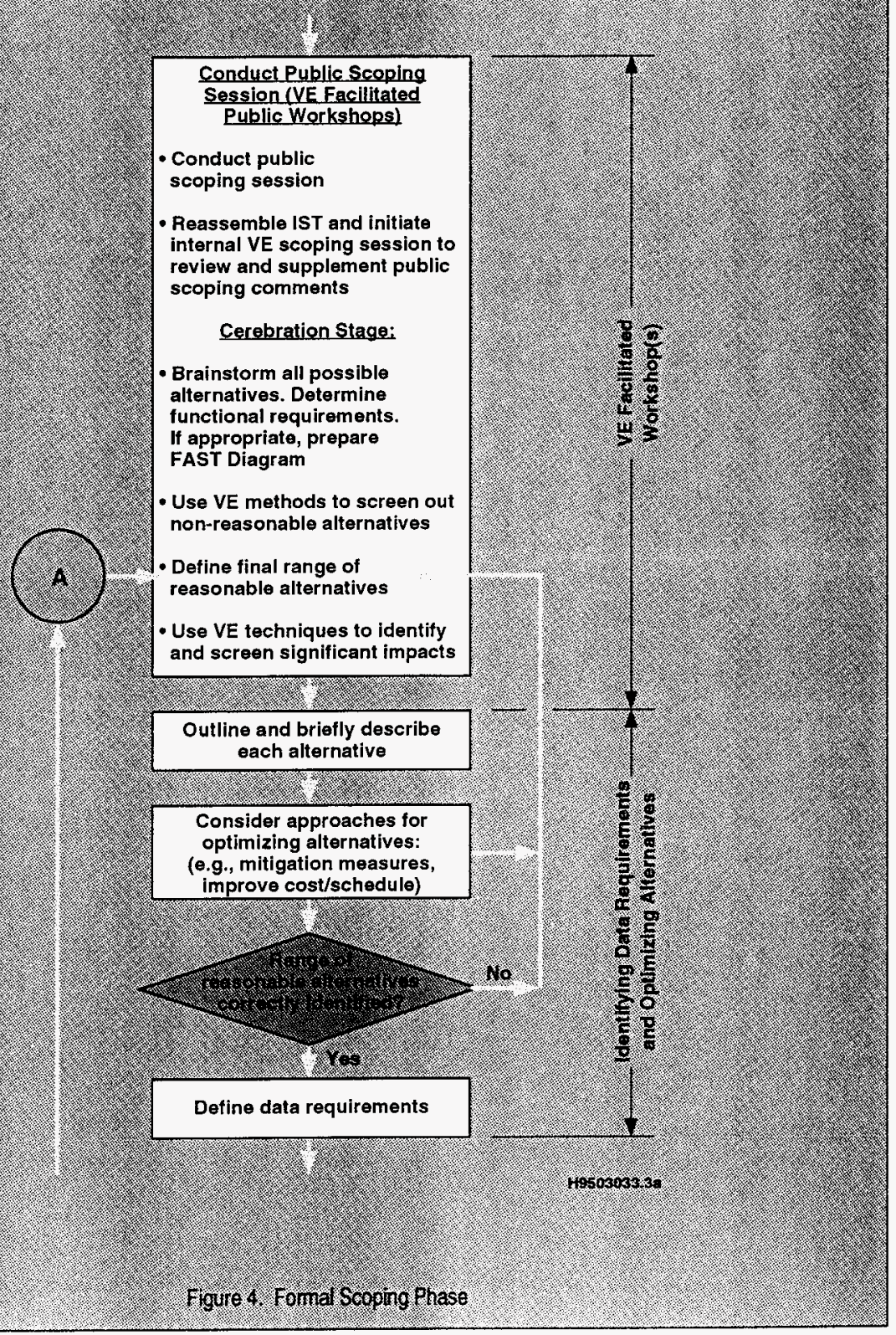




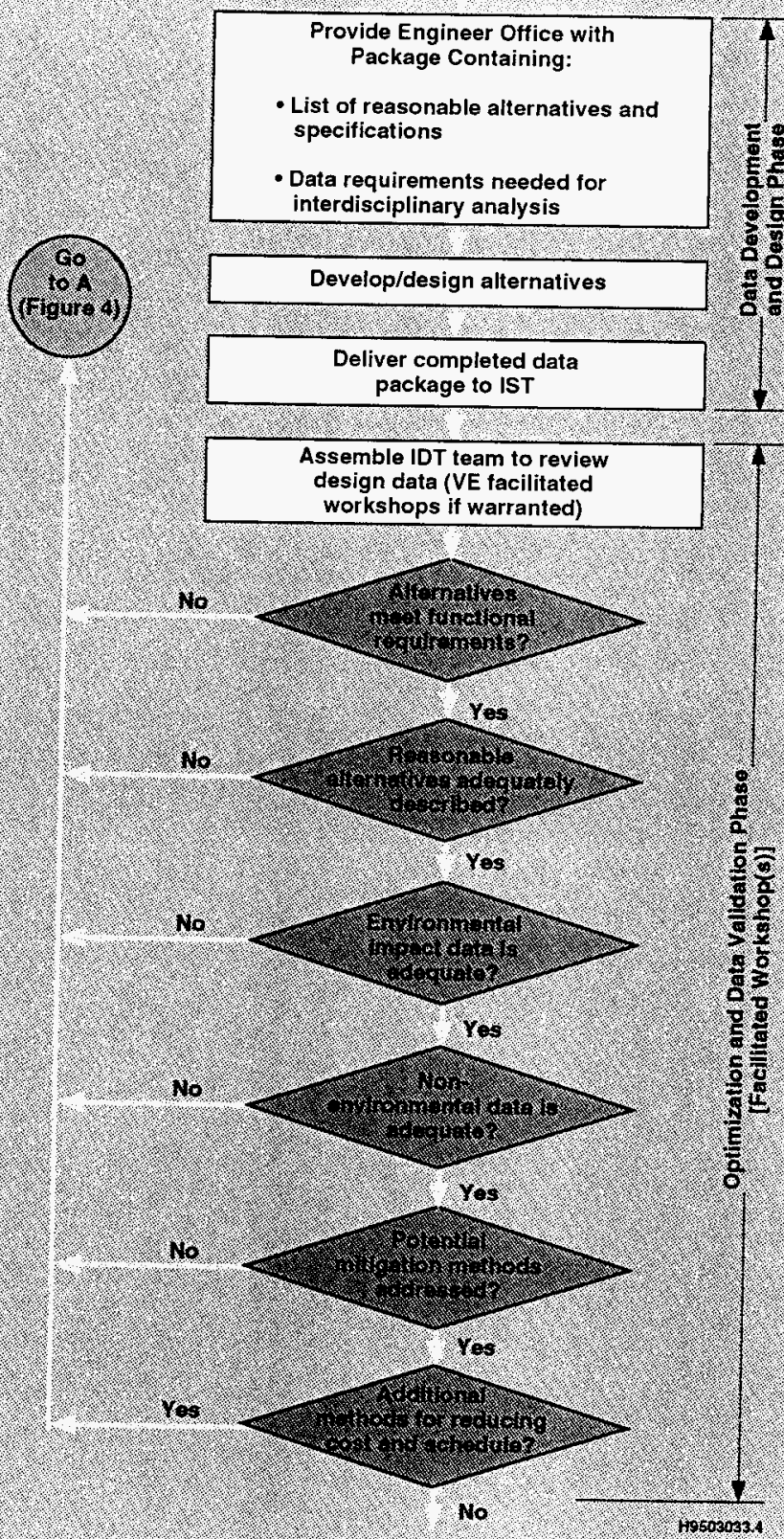

Figure 5. Oata DevelopmentDesign Phase and the Optimization Data Validation Phase 


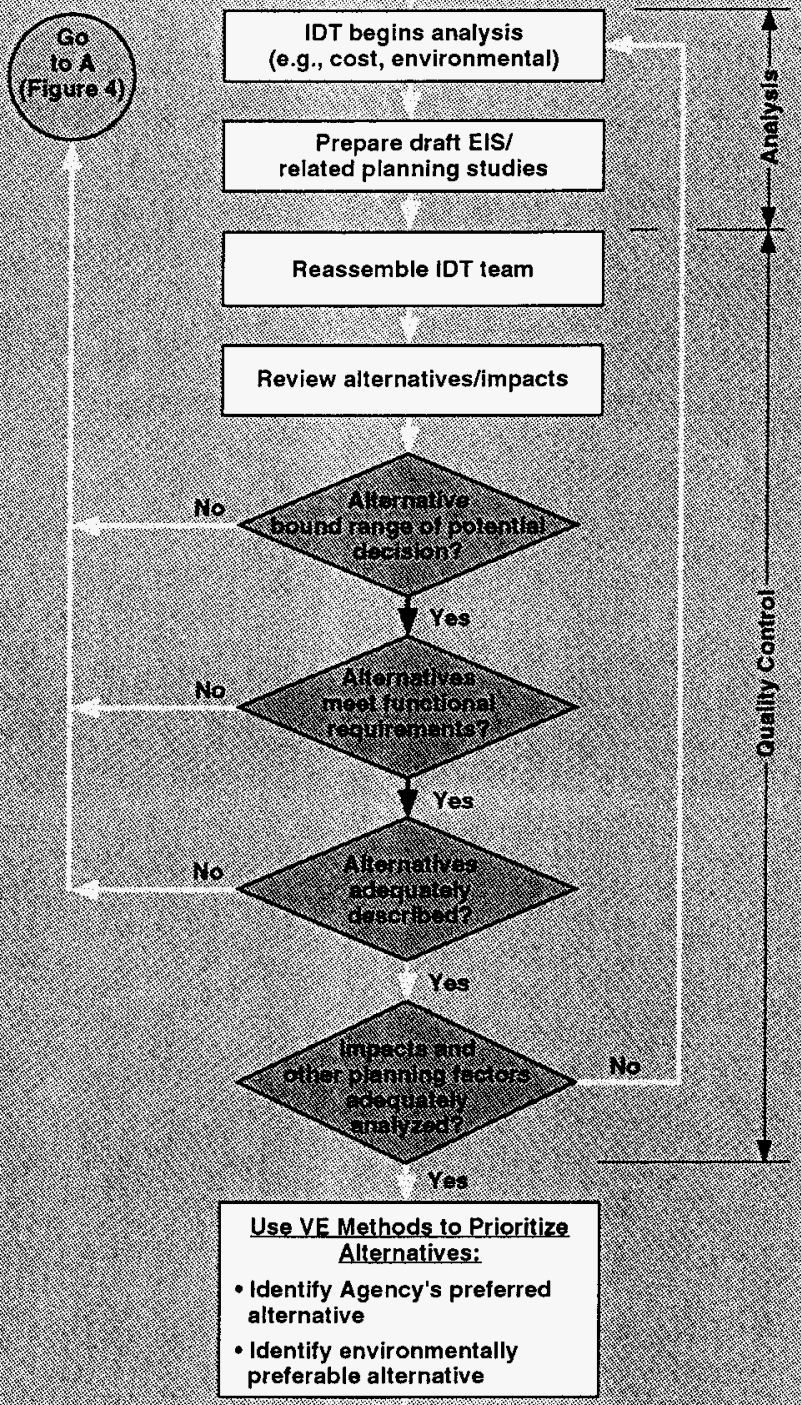

0.00000507

Figure 6. The Anatysis and Quality Control Phase 


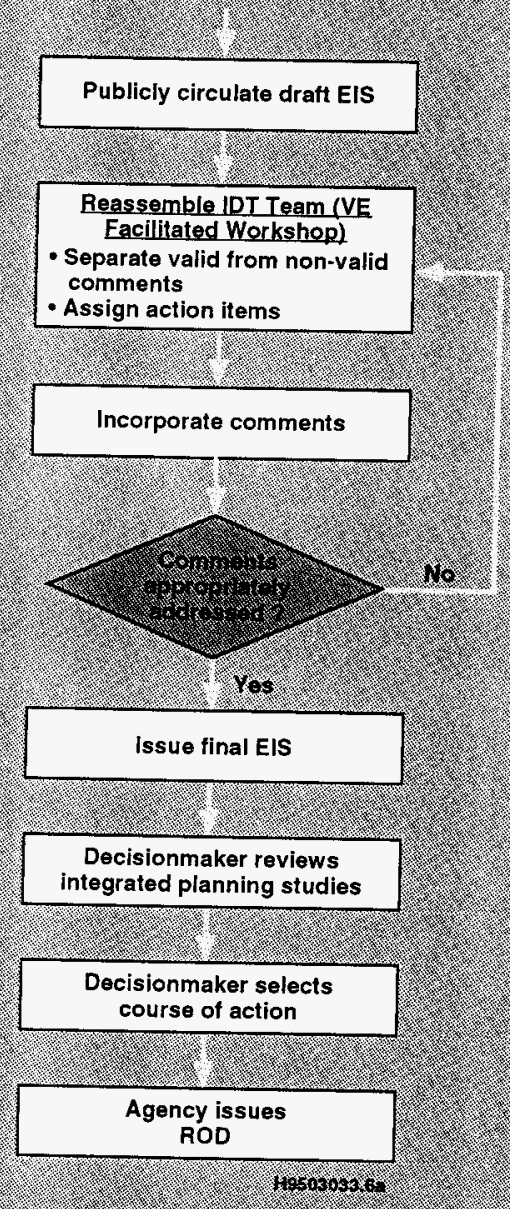

Figure 7 . Revey and Decisionmakting fhase 


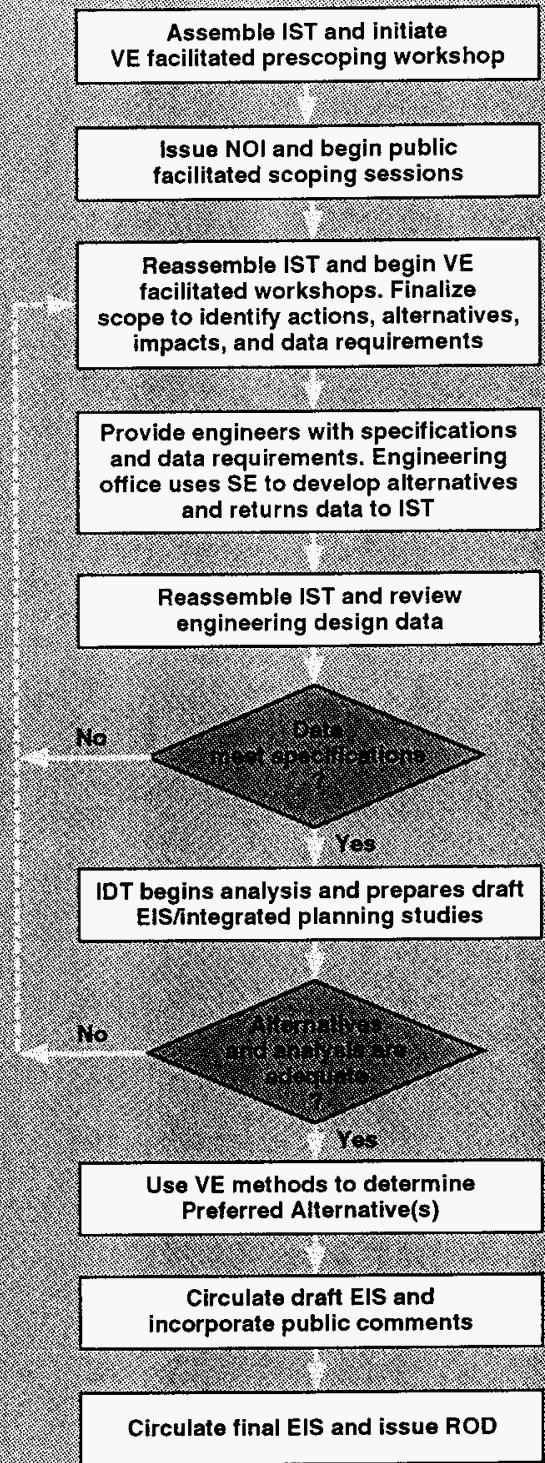

7205080317

Figure 8. Ovenvew of Integrated VENEP A Process 
The IST should not be confused with the IDT. The IDT refers to the team of technical specialists, scientists, and analysts responsible for conducting the actual planning analysis. In contrast, the IST does not prepare the actual planning analysis. Instead, the IST manages the entire planning process, instills an open and objective atmosphere, and ensures that all reasonable alternatives have been considered and are integrated into a comprehensive planning process. In reality, members of the IST might also participate in the analysis as part of the IDT, and vice versa.

\section{Advantages to the Project Manager}

The project proponent does not actually relinquish control of the project. Instead the up-front planning is shared among all pertinent planning entities. Properly executed, an interdisciplinary planning approach can expedite project implementation and reduce cost. Experience indicates that when various entities within the agency become involved in the planning process, they begin to develop a sense of ownership in a successful outcome. Not only will the planning entities have greater appreciation for the need to take action, they are also better able to identify and address potential road blocks, which would eventually face the project proponent. Thus, once a final decision has been reached, the project proponent might find loyal proponents who can be counted on to resolve potential snags during implementation.

\section{INITIATING A FACILITATED WORKSHOP USING VE TOOLS}

Once the IST has been assembled, a facilitator leads a pre-scoping workshop using VE tools and principles. The facilitated workshop is conducted before publishing the EIS Notice of Intent (NOI). This workshop is to quickly determine preliminary factors and information that need to be considered early in the planning process. This information supports the IST during the formal scoping process that follows. The interdisciplinary nature of the workshop helps ensure that all pertinent planning factors are correctly identified and considered. The facilitator keeps the session focused and on track. Guided by an experienced facilitator, the efforts of the IST can be intensely focused, and a surprising amount of work can be accomplished in a very short period. Specific objectives of this workshop are described as follows.

\section{Identifying Other Planning Requirements}

One of the first tasks considered by the IST during the workshop is identification of all applicable planning requirements and organizations that need to be represented and integrated under the NEPA umbrella. If not already included, other disciplines should be added to the IST. 


\section{Defining the Underlying "Need"}

Another task of the workshop is to succinctly define the underlying need for action. Webster's dictionary defines the term "need" as "a want of something requisite, desirable, or useful." While the concept of the need might appear intuitively obvious, on closer examination there are often disagreement and confusion regarding the 'underlying' need. This is a pivotal step, because the underlying need drives the range of alternatives, investigated during the later analysis phase. ${ }^{22}$ Not surprisingly, a change in the definition of need can have profound implications on alternatives identified for later analysis. Correctly defining the need at this step can substantially improve the effectiveness of agency planning and decisionmaking that follows.

Once consensus has been reached regarding the need, the IST defines the purpose for taking action. The term "purpose" should not be confused with the "need." Webster's dictionary defines purpose as a "goal or object to be obtained." Selected VE techniques can be used to ascertain both the need and the purpose for taking action. Because no EIS will be effective if it does not adequately address decisions that need to be made, the IST also identifies the types of decisions that decisionmakers might eventually have to consider, and for which the EIS must address.

\section{Investigating the No Action Alternative and Identifying Functional Requirements}

The IST also could be tasked with the goal of preparing a Functional Analysis System Technique (FAST) diagram on activities currently being performed as part of the no-action alternative. In some instances, a FAST diagram provides a useful tool for understanding the current baseline, identifying and investigating functional requirements and relationships, challenging preconceived assumptions and ideas, and identifying alternatives that might otherwise be overlooked. Resource and infrastructure requirements and other planning considerations are also identified as appropriate. In some circumstances, a FAST diagram might contribute valuable information while in other cases little might be gained from its use. For this reason, one must exercise prudence in determining the appropriate use and application (if any) of a FAST diagram.

\section{The Cerebration Stage: Identifying Preliminary Alternatives and Impacts}

Promoting an atmosphere that encourages innovative thinking is a cornerstone of the TFP strategy. The cerebration stage emphasizes 'thinking outside the box'. Brain storming, a technique often used in VE, provides a proven methodology for achieving this goal. During this phase, the IST considers every conceivable approach for identifying alternatives that meet the agency's underlying need. The goal is to 'leave no stone unturned' in flushing out new approaches. The facilitator maintains an open and nonhostile atmosphere where prevailing assumptions, mindsets, and paradigms are openly challenged in an effort to identify potential courses of action. Preconceived and prejudicial notions are openly challenged as the IST seeks to identify alternatives that might otherwise be overlooked. 
The IST next examines each of the alternatives in an early effort to identify potentially significant impacts or issues that could be encountered. The interdisciplinary format provides an ideal atmosphere for this objective. Identification of potential impacts at this stage alerts the agency to issues that might later be confronted. Consistent with the TFP philosophy, a review also is conducted to identify nonenvironmental planning considerations and factors that need to be investigated to provide information sufficient to support a reasoned decision.

\section{Completing the Pre-Scoping Phase}

Once the facilitated workshop has been completed, attention turns to identifying preliminary environmental and regulatory drivers. A preliminary matrix is prepared of potential regulatory requirements versus alternatives that might be analyzed. The regulatory matrix provides a 'heads up' so that the agency is not surprised by unanticipated requirements. The stage is now set for preparing the NOI, which completes the prescoping phase.

\section{THE FORMAL SCOPING PHASE}

Once the NOI has been issued, the agency is ready to begin the Formal Scoping Phase, depicted in Figure 4. As described in Pre-Scoping, modern management principles, such as VE, are used to enhance the formal scoping process.

\section{USING VALUE ENGINEERING TECHNIQUES TO CONDUCT PUBLIC SCOPING MEETINGS}

In addition to the general public scoping process, some agencies have been pursuing alfernative public involvement efforts, such as conducting "focus group meetings," specifically directed at seeking in-depth comments from special interest groups or parties possessing a high degree of technical insight. Facilitated workshops offer a useful tool for managing and enhancing the effectiveness of focus group meetings. Properly conducted, a publicly facilitated workshop promotes an open atmosphere where prevailing assumptions and mindsets are challenged in an effort to identify innovative and imaginative alternatives that might otherwise go unnoticed. This approach also has the advantage of ensuring that each participant has an opportunity to provide feedback and voice opinions. Specific VE techniques, such as preparing problem/issue statements and group brainstorming methods, might be used to identify alternatives and issues.

One approach for enhancing the effectiveness of public focus group meeting is to divide participants into small groups, based on the interests and concerns voiced by the participants. The facilitator assigns each group specific issues to examine. One group, for example, might be requested to identify potential alternatives while a second group considers potential mitigation measures. A third group could consider important impacts and issues that need to be analyzed in 
the EIS. Brainstorming techniques are used to identify potential alternatives and impacts that need to be investigated. The groups are reassembled and other techniques are applied to eliminate, combine, sort, and rank, the potential alternatives, impacts, and issues for eventual study.

\section{CONDUCTING AN INTERNAL VE WORKSHOP TO SUPPLEMENT PUBLIC SCOPING PROCESS}

On completing the public scoping sessions, the IST is reassembled. Where appropriate (e.g., voluminous or complex scoping comments have been received), a facilitated workshop is conducted internally within the agency to review the public comments. VE management techniques, such as matrix methods, could be used to screen, combine, and group scoping comments into various categories. Once comments are grouped, the IST reviews, evaluates, and prioritizes the scoping issues.

In concert with this effort, the IST supplements the public scoping session with an internal session to finalize any unresolved issues, to provide further clarification, or to investigate potential alternatives and issue in more depth. An internal scoping session, similar to that conducted during the pre-scoping phase, might be performed to supplement the public session. The internal scoping session might add value because agency specialists are often in a position to explore technical issues in greater detail than might be possible in a general public setting.

Unlike public scoping, the internal scoping session is not restricted to consideration of environmental issues. Consistent with the TFP strategy, all pertinent planning factors are captured during this internal scoping effort. Public scoping comments are combined with this internal session to produce a final scope for a comprehensive planning analysis. At the conclusion, results of the internal scoping session (relevant to environmental concerns) are released to the public. Specific efforts performed during this internal workshop are described in the following sections.

\section{Cerebration Stage: Considering All Possible Alternatives}

A brainstorming effort is used to explore potential courses of action that might have been overlooked. Emphasis is placed on promoting an atmosphere that encourages free exchange of ideas and thinking 'outside of the box'. A list of functional requirements and constraints that the preferred alternative must meet is prepared.

To promote a more objective analysis, the TFP strategy intentionally avoids identification of a proposed action. Instead, a set of reasonable alternatives is identified for later analysis. A proposed action is not identified. Forces tending to influence an analysis in favor of a particular direction are therefore reduced because efforts are not concentrated in favor of a particular course 
of action. Ultimately, this approach provides a greater opportunity to actually identify the alternative, best meeting all planning requirements.

\section{Screening and Identifying the Range of Reasonable Alternatives}

The list of alternatives generated during the brainstorming session might be much larger than the range that could reasonably be analyzed. Where appropriate, VE techniques, such as matrix methods, are used to systematically dismiss, combine, sort, and rank potential alternatives in an effort to screen or reduce this list to a manageable "range of reasonable alternatives" for later analysis.

One approach, for example, consisting of two distinct stages, provides a useful methodology for screening attributes. During the first stage, the group identifies alternatives that are clearly unreasonable, and can therefore be eliminated from further consideration. Specific elimination criteria for distinguishing reasonable from unreasonable alternatives should be established to provide a systematic basis for making such determinations. Group consensus is used to remove unreasonable alternatives from further consideration. Next, the facilitator leads the group through an exercise designed to identify alternatives that are similar. Similar or duplicate alternatives are combined where appropriate

\section{Identifying and Screening Significant Impacts}

Because impacts are a function of the specific alternative under consideration, identifying significant impacts begins after the IST has reached consensus regarding the range of reasonable alternatives for detailed analysis. This task is performed by the IDT and might or might not involve the IST members.

The IDT might also use a facilitated workshop to manage this effort. To adequately reflect all potentially affected resources, the IDT workshop includes specialists representing a cross-section of potentially impacted disciplines. Brainstorming or other techniques are employed to review each of the alternatives, and to identify potential impacts and issues for later analysis. An interdisciplinary workshop allows experts representing all affected disciplines to interface, advancing the understanding of interrelationships between environmental resources, impacts, safety issues, and engineering constraints. Environmental disturbances and impacts that might otherwise go unnoticed are more likely to be identified.

For example, a geotechnical engineer might recognize that a proposal to construct a tree farm on a hill would require construction of an irrigation system that could result in the infiltration of water along the hill slope. This information alerts a geologist, who understands that the infiltration has the potential to instigate landslides along an interbedded clay layer that underlies the hill slope. A hydrologist is now forewarned that landslide debris could be transported into a 
stream meandering near the base of the hillside, affecting water quality several miles downstream. Finally, a biologist becomes aware of the fact that a spawning site for an endangered species could be affected by construction of a tree farm, on a hill, several miles upstream. Lacking an interdisciplinary team, such relationships could go unnoticed.

Once these impacts and issues have been identified, data management methods such as VE matrix techniques can be used to screen and group potentially significant impacts from those deemed to be insignificant.

\section{OUTLINING AND OPTIMIZING ALTERNATIVES}

After consensus has been reached, a brief document is prepared describing each of the alternatives. This document provides only enough detail so engineers and analysts understand the scope and specifications of the alternatives. Based on this document, engineers and analysts will be tasked with responsibility for 'developing' the alternatives to the point where there is sufficient detail to support an adequate analysis.

Next, a TQM stage is executed in an effort to optimize the alternatives. The IST reviews each alternative, searching for methods of optimization (e.g., performance specifications, cost, schedule, environmental considerations, and mitigation measures, and other considerations). Emphasis is placed on identifying methods for reducing cost and schedule delays.

If appropriate, a FAST diagram might be prescribed for each of the identified alternatives. The diagram could be used to challenge prevailing ideas, questioning the actual need for conducting individual activities within a given alternative, and to search for more cost effective and environmentally sound approaches.

The loop shown in Figure 4 indicates this step might be iterative. The optimization phase could affect the range of reasonable alternatives identified in the earlier scoping process. This step might have limited the range of reasonable alternatives. Thus, a final check is made to ensure the analyzed alternatives still encompass the range of all reasonable alternatives.

\section{DEFINING DATA REQUIREMENTS}

Once the alternatives are briefly outlined and potentially significant impacts have been identified, the next step is to define specific data requirements necessary for performing the NEPA analysis and other integrated planning studies. Data requirements could involve parameters such as emissions, effluents, estimates of ground disturbance, and natural resource requirements. Non-environmental data requirements might include factors such as cost-benefit data, reliability, performance projections, and time schedules. 
Accurate identification of requirements is a critical step. In some cases, entities might have a vested interest in generating data, even if the need for such information is questionable. In other cases, necessary data might have been overlooked or not properly identified. An important feature, distinguishing the TFP process from many other approaches, is that data requirements necessary for the subsequent analysis are defined by an independent body-the IST. The IST in cooperation with the IDT provides the independence and interdisciplinary expertise necessary to provide an objective analysis, which minimizes problems discussed earlier. Engineering and technical groups are not left with the problem of having to second guess specific data requirements. Because data requirements are identified in an open, interdisciplinary forum, data are much more likely to be generated on schedule without wasted effort.

The Scoping Phase is now complete. Data requirements, along with a brief but concise description of the alternatives, are presented to the project proponent (engineering or design office) for detailed development. This office is responsible for preparing a specific description of the alternatives and generating technical input data necessary for conducting the integrated planning analysis.

\section{DATA DEVELOPMENT/DESIGN PHASE}

The TFP process now enters a Data Development and Design Phase depicted by the first three boxes in Figure 5. Where appropriate, systems engineering provides the structured basis for developing designs, coordinating technical efforts, and ensuring quality of the data for the analysis phase. Specialists skilled in SE are employed to oversee this step.

Based on the specifications and data requirements provided by the IST, a technical group consisting of engineers/technical specialists develops specific descriptions of the alternatives and generates technical data, sufficient to support an integrated analysis that will be conducted by the IDT. Depending on the nature of the potential actions, this step must be tailored to meet specific circumstances. On completion, this data package is transmitted to the IST, according to a specified schedule, for review and validation.

\section{OPTIMIZATION AND DATA VALIDATION PHASE}

On receiving the completed SE data package, the IST/IDT review and validate that the data are complete and meet original specifications (Figure 5). As a TQM measure, Optimization and Data Validation Phase infuses accountability into the planning process by verifying that the data meet original specifications, no more and no less. Thus, the technical group developing the data and alternatives is accountable for ensuring data accuracy and that only specifically requested data have been generated. This step is designed to control costs, improve quality and performance, and to ensure that all reasonable alternatives, identified by the IST, are given equitable consideration. 
This step is represented by the six diamonds (Figure 5). If the data package is large, a facilitated workshop could be convened to review the data package based on criteria shown in the six diamonds. The facilitated workshop approach ensures that alternatives are 'optimized', and that the agency has the best courses of action available from which to choose (e.g. environmental, cost, schedule, and other decisionmaking factors). If the data are judged inadequate, the proceeding process is reiterated. This step is depicted by the arrow, shown looping back to the box titled "Define final range of reasonable alterative" on Figure 4. In reality, professional judgment is exercised in determining the appropriate bounds of the loop.

\section{THE ANALYSIS PHASE}

After the data have been validated, analysts begin the Analysis Phase, depicted in Figure 6 . Preparation of the EIS document and/or other combined planning studies are performed during this phase. Principles from TQM are used to ensure quality, completeness, and integrity of the analysis, while VE techniques are used to objectively compare and prioritize alternatives. Principles from SE might also used in performing the integrated analysis.

\section{CONDUCTING AN INTEGRATED INTERDISCIPLINARY ANALYSIS}

As discussed earlier, the actual analysis is performed by the IDT. To promote an integrated planning process, relevant planning studies such as risk and cost-benefit analyses are coordinated and integrated with the environmental analysis. Results of these studies might either be integrated directly into the draft EIS document or prepared as separate but tightly coupled studies that would accompany the draft EIS through the agency's decisionmaking process. ${ }^{23}$ Emphasis is given to identifying and addressing inconsistencies with other planning efforts, regulatory considerations, and assessing potential infrastructure and resource requirements. Ultimately, the goal is to produce a comprehensive and integrated study, providing decisionmakers with all pertinent planning factors necessary to reach an informed decision.

\section{INTEGRATING QUALITY MANAGEMENT INTO THE ANALYSIS}

As a TQM measure, the IST is responsible for ensuring that the draft EIS and other related studies meet specific planning requirements. Specifically, the IST ensures that the alternatives will support potential decisions that need to be made (including functional requirements), alternatives are accurate and correctly described, and that alternatives and impacts have been adequately evaluated. This goal is represented by the four diamonds shown in Figure 6. Emphasis is placed on ensuring that the draft EIS meets the agency's underlying need and properly address decisions that need to be made.

If needed, the IST is reassembled to address comments or special issues of concern. The IST also 
is responsible for verifying that the impact analysis is consistent with the originally agreed upon scope. If the alternatives are not adequately described or do not meet the agency's ultimate needs, the process is reiterated. This step is depicted by the upward pointing arrow on the left side of Figure 6, which is shown looping back to the box "Define final range of reasonable alternatives." In reality, professional judgment must be exercised in defining the appropriate bounds of this loop.

Similarly, if the impacts or other planning factors are not adequately evaluated, the analysis is reiterated. This step is depicted by the arrow on the right side of Figure 6, shown looping back to "IDT begins analysis." Again, professional judgment must be exercised in determining the bounds of this loop.

\section{USING VE TOOLS TO DETERMINE THE PREFERRED ALTERNATIVE}

The NEPA regulations require that, where possible, agencies are to identify their "preferred" alternative(s) within the draft EIS. The preferred alternative can be based on a myriad of factors, including environmental, economic, and technical considerations. ${ }^{24}$ The agency also must identify the "Environmentally preferable" alternative(s) in the Record of Decision (ROD). ${ }^{25}$

As discussed previously, to promote a more objective analysis, the TFP approach intentionally avoids identifying a proposed action. Consistent with this objective, identification of the agency's Preferred Alternative has been intentionally delayed until this phase in the planning process. If appropriate, a short facilitated session could be performed to identify these altematives. VE techniques provide effective tools for objectively comparing, discriminating, and prioritizing the relative merits of the alternatives, in an effort to identify the alternative( $(s)$ that best meets all planning considerations. Pertinent decisionmaking factors such as environmental impacts, schedules, cost, and performance factors are considered together. Similarly, the environmentally preferable alternative is also identified.

A method referred to as the nominal grouping technique can be used to rank and prioritize the alternatives. Each member of the IST is instructed by the facilitator to identify one or more alternatives believed to be optimum from the standpoint of factors such as economics, performance, and environmental quality. Participants rank their selection of alternatives in terms of their relative merits (highest too lowest). Special techniques are used to assimilate each member's selection in an effort to achieve a group consensus.

\section{REVIEW AND DECISIONMAKING PHASE}

The Review and Decisionmaking Phase completes the TFP process (Figure 7). The draft EIS (and/or combined planning documents) are circulated for public review and comment. If warranted, the IST could be reassembled and VE tools used to screen, combine, and group public 
review comments. The team determines appropriate comment responses for incorporation into the EIS. As a TQM measure, a formal review is performed by the IST to ensure that all comments were appropriately addressed and incorporated.

On completing this review, the final EIS is issued. Normally, the IST makes a recommendation to the decisionmaker regarding an appropriate course of action. Once the final decision has been made, the ROD is issued to publicly record the agency's final decision. The IST is dissolved and implementation of the selected alternative is turned over to a project proponent or project engineering office.

\section{CONCLUSION}

Conceptually alluring in its simplicity, concinnity is the key ingredient, essential to the success of a comprehensive and holistic federal planning process. In a time when Congress is striving to "re-engineer" the governmental apparatus, the TFP strategy offers a systematic approach for achieving concinnity, by unifying the disjointed planning processes currently used by many federal agencies. The TFP strategy offers clear advantages over current approaches used by most federal agencies in planning actions because it enhances the ability to: determine an optimum course of action; increases understanding of interrelationships; tradeoffs are easier to identify and analyze; potential conflicts are easier to identify and diagnose; reduces redundancies, inconsistencies, miscommunications, and problems that may otherwise go unrecognized; and enhances understanding of infrastructure and resource requirements. When implemented using skilled professional judgement, such advantages will substantially improve the entire federal planning process while reducing the time and cost.

\section{ACKNOWLEDGMENTS}

I wish to thank Mr. P. F. X. Dunigan Jr. (U.S. Department of Energy, Richland Operations Office) who reviewed this paper and contributed valuable suggestions. Special thanks is extended to Mr. R. H. Engelmann (Manager, Hazardous Waste Services ) who encouraged development of this approach, and Ms. A. Weiner (Manager, Environmental Management Services), and Ms. G. Cummins (NEPA Team. leader) and J. Granger of Waste Management, Federal Services of Hanford (WMH) Inc., who actively supported development of the Total Federal Planning Philosophy. Mr. J. Gould (Environmental Management Services, WMH) deserves special mention for contributing valuable comments which significantly enhanced the quality of this paper. Finally, I would like to express appreciation to Ms. C. Hays (technical editing, WMH), and Mr. Rob Hedges and Ms. D. Austin (graphics, WMH). 


\section{REFERENCES}

1. The National Environmental Policy Act of 1969, as amended (Public Law 91-190, 42 United States Code 4321 4347, January 1, 1970).

2. CEQ, Regulations for Implementing the Procedural Provisions of the National Environmental Policy Act, 40 Code of Federal Regulations (CFR) 1500-1508.

3. 40 CFR 1500.5, 1501.2, and 1506.4.

4. 40 CFR 1501.2, 1501.7, and 1502.14(a).

5. 40 CFR 1502.2 (c)

6. 40 CFR 1501.2

7. 40 CFR 1502.14 (a)

8. Miles, L. D., Techniques of Value Analysis and Engineering, McGraw-Hill, N.Y., 2nd Edition, 1972

9. Office of Management and Budget Circular No. a-131.

10. 40 CFR 1500.1 (b), 1500.2 (b) and (d), and 1501.4 (b).

11. 40 CFR $1502.2(\mathrm{~g})$ and 1502.5

12. 40 CFR 1502.14

13. 40 CFR 1501.2 and 1507.2

14. 40 CFR 1500.2(c), 1500.5, 1501.2, $1501.2(\mathrm{a}), 1501.7(\mathrm{a})(6)$ and (b)(4), 1502.25(a), 1505.2, and 1506.4

15. $1500.5(\mathrm{a}), 1500.5(\mathrm{f}), 1501.1(\mathrm{a}), 1501.2$

16. 40 CFR 1502.5

17. 40 CFR 1502.1

18. 40 CFR 1502.14(a)

19. 40 CFR $1500.2(\mathrm{e}), 1502.1,1502.14(\mathrm{a})$ and (c)

20. Systems Engineering Management Guide, Defense Systems Management College, Fort Belvoir, Virginia, U.S. Government Printing Office, January 1990. 
21. 40 CFR 1501.2

22. Schmidt, O. L., The Statement of Purpose and Need Defines the Range of Alternatives in Environmental Documents, 18 Environmental Law 371-81, 1988.

23. 40 CFR 1506.4

24. 40 CFR 1502.14(e)

25. 40 CFR 1505.2 (b) 